\title{
Research on Accounting Talent Training in Financial Shared Service Model
}

\author{
Meifang Liu \\ Gansu Normal University for Nationalities \\ Hezuo, China 747000
}

\begin{abstract}
The financial shared service is a kind of management modes that bring the common functions within the group together. And then, it can provide standardized services to all business units with high quality and low cost. It can improve the standardization and efficiency of enterprise accounting information treatment, which is an effective way to enhance the level of enterprise financial management. The development of technology and the reform of enterprise financial management mode have put forward higher requirements of accounting personnels, which will inevitably lead to deep thinking about the cultivation of accounting talents in colleges and universities. In this paper, the author has put forward concrete measures to cultivate applied accounting talents from the aspects of accounting personnel training objectives, curriculum system settings, innovative teaching methods, construction of teaching staff, and so on. And then, the colleges may cultivate accounting talents to meet the social needs.
\end{abstract}

Keywords-shared finance; accounting reform; talent training

\section{INTRODUCTION}

Accounting talents are important foundation for the economic and social development in our country. The colleges and universities, as the bases for training talents, have direct impact on the working ability, professional quality and moral cultivation of accounting practitioners. With the development of financial shared services, the traditional financial thinking has been far from meeting the development needs of modern enterprises. The construction and development of enterprise financial shared centers has replaced the traditional accounting such as posting accounting, statement accounting and cost accounting. Financial organizations have been transformed from accounting department to three major types. And "strategic finance" supports major decisions and focuses on management. "Business finance" focuses on control, communication and management. "Shared finance" handles financial statements and revenue and expenditure in the financial shared center.

Thus, the structure of accounting staff would face a huge change. Under the financial shared service, a few accountants enter the financial shared service center and engage in simple and repetitive information entry. The basic accounting work embodied in the traditional accounting functions would gradually be replaced by the information technology of the shared service center. Simple accounting services gradually reduce, or even disappear. Therefore, the accounting work in the future may be polarized. One of the accounting works is simple and repetitive information entry, and non-accounting personnel can also participate in post competition. The other one of the accounting work will become high-end. It includes strategic finance, business finance, management decision-making, which will be the work of the strong and the wise man.

\section{THE DEVELOPMENT AND REQUIREMENTS OF FINANCIAL SHARED SERVICE MODEL}

With the economic globalization and the global industrial chain layout of large enterprises, the accounting business has become more and more complicated. The finance is no longer just the accounting and payment, but requires the combination of finance and business. And the finance should intervene in the business operations of enterprises. On the one hand, it must achieve the concentration of financial functions. On the other hand, the finance must achieve the intervention into the business. Promote finance from the corporate strategy to help businesses achieve business goals, the request of the achievements of the financial sharing service model. From the strategic level of enterprises, it promotes the finance help enterprises achieve business objectives. With this requirement, it has promoted the achievements of the financial shared service model. In recent years, many companies in our country adopt the financial shared service mode for daily accounting and financial management. And financial shared has gradually become an important mode of enterprise financial management. On December 9, 2013, in the notice of the ministry of finance on the issuance of the regulations on enterprise accounting informatization, article 34 clearly states that "the large-scale enterprises with many branches and subsidiaries should explore the Information technology to promote the concentration of accounting work. And then, it would gradually establish a financial shared service center, which also provides strong policy support for the development of financial shared services.

With the promotion of the strategic goal of "the Belt and Road", the number of enterprises implementing the strategy of "going out" has been increasing year by year in our country. It can be predicted that a large number of enterprises would establish financial shared services. And the 
financial shared services are no longer exclusive to the companies. It is ideal choice for financial accounting of large, small and middle-sized companies.

The rapid development of financial sharing will inevitably lead to changes in the demands for qualified personnel. The reform of higher education urgently needs to follow the market demand for accounting talents in the new situation.

\section{THE ESSENCE OF FINANCIAL SHARED SERVICE AND ITS REQUIREMENTS FOR THE ABILITY OF QUALIFIED PERSONNEL}

\section{A. To Clarify the Essence of Financial Shared Service}

Financial shared service would rely on information technology. And it would be scattered in various business units to reengineer high-repetition and standardized financial business. And then, it can focus on unified treatment. The physical accounting business in different countries and locations will be aggregated to make accounting and reporting in financial shared service center. And it would ensure the standardization and unified structure of accounting records and reports. A company has reached certain scale with a large number of branches, and the business is relatively simple. The headquarters have centralized financial management, and strengthen the management needs of branches. Then, the enterprises can consider providing financial shared service. The establishment of financial shared service can optimize the internal organizational structure and standardize the business process. And it could reduce the operating costs of enterprises, improve the efficiency of accounting, and reflect the higher independence of accounting and strong monitoring ability. Due to the uniform caliber of accounting data, it can reflect the fairness and other advantages of performance appraisal.

Financial shared service centers can also provide compensable service to the outside world. Small and medium-sized micro-enterprises can outsource accounting to the financial shared service center. It means that the financial shared service center wouldn't only affect the accounting practitioners of large enterprises, but also affect the accounting practitioners of small and medium-sized microenterprises. And its impact on the field of accounting is comprehensive.

\section{B. The Capacity Needs Based on the Business Finance}

Under the financial shared service mode, accounting is no longer a pure economic information system, but a value management activity. In order to enable students to adapt to the new role as soon as possible, undergraduate education in colleges and universities should focus on business finance, and cultivating students' business financial ability.

1) Comprehensive quality: Students should have the correct ideology and morality, professional ethics, good attitude, optimistic attitude towards life, critical and logical thinking, the ability of communication and coordination, sense of responsibility, creativity and enterprising spirit.

2) Knowledge structure: Students should pay attention to cultivate the knowledge structure, master the financial accounting, management accounting, financial management, business management, computer and other professional knowledge. Students should master financial laws and regulations, accounting systems and guidelines, related knowledge and skills of financial management. Students should be familiar with the latest trends of the development of business. And they should have abilities of systematic, global, proactive thinking.

3) The performance of ability: The colleges and universities should require students to have strong ability of logical thinking, learning ability and writing ability. The students should better use the knowledge to find problems, analyze problems and solve problems. Students should have strong planning and implementation capabilities.

\section{The Ways of Accounting Personnel Training UNDER THE BACKGROUND OF FINANCIAL SHARED SERVICE}

The colleges and universities are important positions for training qualified personnel. In the new era, they should vigorously promote business finance, strategic finance and the new model of financial shared service. With the continuous expansion of demand dimension and hierarchy of accounting personnel, all the aspects of higher education of accounting will also constantly undergo reforms.

\section{A. To Optimize the Accounting Personnel Training Programs}

1) To refine training objectives: Under the financial shared service, the focus of accounting service is advanced from accounting to management, which enhances the ability of accounting staff to work well. At the same time, it requires the adjustment of the training goal of accounting higher education. In the goal of personnel training, it is necessary to highlight the cultivation of comprehensive ability of students, but also to strengthen the promotion of professional ethics and humanistic spirit. Through the establishment of the correct training objectives, the teaching of accounting higher education would be more directional. And then, it can train qualified professionals.

2) To build a curriculum system: Under the financial shared service, accounting higher education is multidisciplinary and multi-level integration. And then, it could achieve the goal of perfecting the knowledge system of students. Students are required not only to be familiar with the accounting expertise, but also to have the ability to make analysis and decision, teamwork and develop students' ability to analyze and solve problems. First, the promotion of the basic accounting course system is the foundation of the accounting teaching. Accounting education must pay attention to the basic accounting, financial accounting, cost accounting and other professional disciplines. Also, the students should develop solid accounting basic knowledge. 
Under this premise, we will focus on building directional curriculum such as internal control, financial management, strategic management of the company and risk management in accordance with the principle of curriculum construction and practical results based on professional training objectives. And then, it could enhance students' financial analysis and decision-making ability. Second, with the requirements of sustainable development of enterprises and management accounting ability, it needs to set up courses on company operations, budget management, performance analysis and risk management to cultivate students' strategic thinking and interpersonal communication skills.

3) To optimize curriculum resources: In order to optimize the curriculum resources, we must reset the syllabus, teaching points and requirements, reference resources and other resources according to the condensed training objectives. Then, we should focus on the optimization of teaching videos, PPT, exercises and cases and other resources. For the video production of the course, knowledge points of the teaching contents should be fragmented according to the learners' best attention time and memory rules of online learning. And the questions and answers should be properly designed to consolidate practice and interest in learning process.

4) The Construction of practical teaching system: In the accounting undergraduate education, the colleges and universities could build progressive practice curriculum system. And this system would show gradual teaching framework. The main arrangement is to carry out manual simulation training after each stage of the study of accounting principles, intermediate financial accounting and cost accounting to deepen the cognition of accounting. And then, the colleges and universities could set up comprehensive simulation training to reflect the practical course from shallow to deep process. At the end of the second grade, the colleges and universities should carry out vocational experience courses, organize students to enter into enterprises, securities companies, groups and other places to visit and learn, understand business processes, and feel the corporate culture. At the end of the third grade, the colleges and universities should develop vocational training, organize students to enter into enterprises and institutions, group companies and other places to participate in business training, further understand professional knowledge and experience practical operation. In the fourth grade, the students should have professional internship outside the colleges. On the basis of the previous study, students should master manual operation, consolidate the professional knowledge and enhance the comprehensive ability.

\section{B. To Strengthen Teaching Activities and Supervision}

1) To hold skills competition actively: And the colleges and universities should guide and encourage students to hold and participate in subject competitions, encourage students to build cross-disciplinary teams to participate in college accounting information competition and ERP simulation contest. And then, they can cultivate students' innovative practice ability through discipline competitions.

2) The reasonable arrangements for learning activities: Classroom teaching focuses on in-depth analysis and discussion of problems and cases. At the same time, it would organize classwork and after-school testing. Student could ask questions, and the teachers would solve the problems encountered in learning. Then, they would also expand students' thinking, and guide students to think actively. In the end, they would improve students' logical thinking ability, learning ability and the ability of finding problems.

3) The innovation of assessment mechanism: The colleges and universities should change assessment methods, attach importance to the overall quality evaluation, make the integration of achievement evaluation and process evaluation, and use various ways to have assessment, such as homework, case analysis, class questions, manual simulation, learning experience, learning summary, dissertations, skills competitions and other forms. And the students can get scores from all of assessment. And it is a comprehensive examination. Then, it also should increase the proportion of practical ability evaluation. Usually, students' learning is not positive. They only review the focus before the examination. And the teaching is not ideal. The colleges and universities should use various assessment methods to create learning atmosphere and enhance learning self-discipline of students.

\section{Rational Utilization of Teaching Resources}

1) To establish and improve the teaching service platform and provide teaching information resources: The colleges and universities should establish and improve the teaching service platform. The library should participate in the classroom teaching. The library resources would serve the teaching platform and provide technical guidance for information retrieval and resource application. And then, it would deepen the applications and requirements of information literacy of teachers and students. Second, we can collect and process various types of literature resources. And then, we can integrate these resources as the knowledge point of the course to support and improve the teaching content.

2) To strengthen industry-academy cooperation: In the process of theoretical study and practice training, the students should have ERP SANGBOX simulation experiment. By simulating the business environment and processes, we can simulate functional positions and allow students to experience the fierce and brutal competition in the market. And then, the students would experience the operational risks and responsibilities. Students experience the strength and advantages of team collaboration in practical confrontation. Students would master management skills. Also, they can understand and master the 
comprehensive knowledge and skills of business management without being out of school, which can improve the students' employment competitiveness.

With the help of accounting simulation laboratory, the agency operation of bookkeeping will be introduced into the school. With the guidance of teachers, the students can provide financial treatment, tax returns and other services for the enterprises. Students would participate in the actual accounting treatment. It would achieve the real combination of theory and practice, and continues to improve the actual combat ability.

\section{The Construction of Teaching Staff}

1) To construct high-quality teaching team: Under the mode of financial shared service, the change of teaching concept and the improvement of informationization will put forward higher requirements on the knowledge level of teacher team. To build multi-level and high-quality teaching team will be an important guarantee for higher education accounting teaching. In order to build a team of high-quality teachers, it must have a leader with noble character, rigorous scholarship, deep academic attainments and innovative academic thinking. And this leader could make long-term commitment to curriculum construction and insist on the teaching for students. Also, the leader should have good organizational management and leadership skills. There are middle-aged and young backbone teachers with reasonable age structure, complementary knowledge structure and balanced title structure. There are also best part-time teachers who have great influence from industries and enterprises. These teachers should have different levels of education background. They should have professional theoretical knowledge, network information technology, practical operation and other expertise. They can complement each other to make up for shortcomings. Also, the teachers should constantly enhance the knowledge and teaching quality.

2) To introduce "double-quality" teachers and promote the development of education: The demand of financial shared service for accounting talents and the update of accounting business knowledge has promoted teachers' knowledge and skills in accordance with the requirements of the times. It has proposed the "double-quality" teachers in accounting education in colleges and universities. That is, teachers should have the theoretical research and the quality of professors in the fields of accounting. Also, the teachers should have the ability to apply the theory to guide the students in practice. It can be seen that "dual-quality" teachers are crucial link and important guarantee for meeting the requirements of the development of the times and achieving talent training. It would directly affect the quality of personnel training. And then, it would have influence on the achievement of the goal of personnel training.

"Dual-quality" teachers can flexibly be consultants, guest professors and part-time teachers according to their needs.
The colleges and universities can hire top management personnel as consultants or guest professors from enterprises. They can participate in the formulation of teaching plans and syllabus. And then, the personnel training would be in accordance with the actual needs of enterprises. The colleges and universities also can hire technicians from enterprises as part-time teachers. And these technicians can teach practical courses. "Dual-quality" teachers can better promote the development of education, deepen the students' knowledge structure, and improve the overall ability of students.

3) To strengthen the training of teachers and improve teachers professional level: The colleges and universities should send teachers to enterprises and institutions to take a temporary post and have exercise. And it would enhance teachers' practical ability. The colleges and universities should strengthen the training of young teachers. And these young teachers should also engage in advanced studies in famous universities to broaden their horizons. Then, colleges and universities should introduce advanced teaching methods and concepts and improve their teaching standards.

\section{CONCLUSION}

The economic and technological development has promoted the change and progress of accounting. The accounting reform has produced the financial shared service mode. The financial sharing service mode has also led to the change of accounting personnel demand. As the universities that cultivate accounting talents, they should adapt to this change, adjust training objectives in time and build the curriculum system. And then, the colleges and universities could deliver qualified talents to meet the social needs.

\section{REFERENCES}

[1] Tian Gaoliang, Yang Na. Discussion on the reform of accounting talents cultivation in colleges and universities based on financial shared service [J]. University Education, 2016, (10).

[2] Zhang Di. Transformation of the management accounting talents under the trend of financial shared service [N]. Accounting-News, 2015 (4), 24

[3] Chen Xiaopeng. Characteristics and cultivation of talent ability in financial shared service center: Based on the experience of company $\mathrm{Z}[\mathrm{J}]$. Finance and Accounting (Financial Management Edition), 2013 , (05).

[4] Yang Hongxia. Reform the mode of talent training and improve the quality of talent training [J]. China Higher Education Research. 2014 (10).

[5] Luan Fugui. On the concept of accounting education [J]. Accounting Research. 2013 (4). 